ABDI: Jurnal Pengabdian dan Pemberdayaan Masyarakat ISSN: 2656-369X (Print), 2684-8570 (Online)

Volume 1 No. 1, Juni 2019

http://abdi.ppj.unp.ac.id/index.php/abdi

Email: abdi@ppj.unp.ac.id

DOI: https://doi.org/10.24036/abdi/voll-issl/1

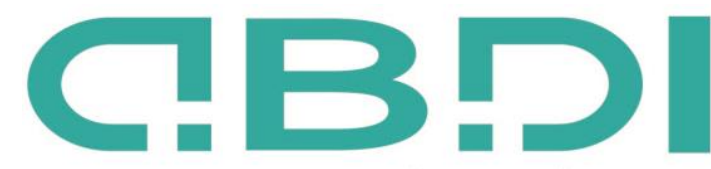

ABDI: JURNAL PENGABDIAN DAN PEMBERDAYAAN MASYARAKAT

\title{
Pemanfaatan Potensi Budaya Lokal dalam Pembangunan Ekowisata
}

\author{
Erda Fitriani $^{1}$, Selinaswati Selinaswati ${ }^{2}$ \\ ${ }^{1,2}$ Jurusan Sosiologi Universitas Negeri Padang
}

Email: fitriani_cim@yahoo.com, selinaswati@fis.unp.ac.id

\begin{abstract}
Abstrak
Pengabdian masyarakat telah dilakukan pada kelompok PKK di Nagari Sungai Pinang Kecamatan Koto IX Tarusan Kabupaten Pesisir Selatan Sumatera Barat. Pelaksanaan pengabdian selama enam bulan, dari bulan Juni sampai November tahun 2018. Masyarakat dapat berpartisipasi terutama kaum ibu-ibu dalam pembangunan pariwisata dengan menggunakan potensi yang dimiliki oleh budaya lokal yaitu sulam bayang sebagai ciri khas dari masyarakat Pesisir Selatan. Tujuannya yaitu untuk peningkatan ekonomi rumah tangga pada masyarakat maritim yang berada di kawasan pariwisata Mandeh. Metode yang digunakan adalah metode partisipasi aktif. Mekanisme kegiatan dilakukan dalam beberapa tahapan yaitu penetapan kelompok sasaran, identifikasi budaya lokal, pelatihan, monitoring dan evaluasi. Hasil dari kegiatan pengabdian ini yaitu meningkatnya animo ibu-ibu PKK untuk bersama-sama mengembangkan budaya lokal sulam bayang sebagai salah satu wirausaha yang dapat membantu peningkatan pendapatan rumah tangga sekaligus melestarikan budaya lokal.
\end{abstract}

Kata Kunci: Budaya Lokal, ekowisata, dan sulam bayang, PKK

\section{Abstract}

Community service has been carried out in PKK groups in Nagari Sungai Pinang, Koto IX Subdistrict, Tarusan, South Coastal District, West Sumatra. The implementation of service is carried out for six months, from June to November 2018. The community can participate primarily in the development of tourism by using the potential of the local culture, namely "embroidery of the shadow" as a characteristic of the South Coast community. The goal is to improve the household economy of the maritime community in the Mandeh tourism area. The method used is the method of active participation. The mechanism of the activity is carried out in several stages, namely the determination of the target group, identification of local culture, training, monitoring and evaluation. The results of this service activity were the increasing interest of PKK mothers to jointly develop the local culture of shadow embroidery as one of the entrepreneurs who can help increase household income while preserving local culture.

Keywords: Local Culture, ecotourism, and shadow embroidery, PKK

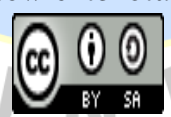

Received: 18 Maret 2019

Revised: 29 Maret 2019

Available Online: 10 April 2019 


\section{Pendahuluan}

Mitra PKM adalah ibu-ibu pengiat Pemberdayaan Kesejahteraan Keluarga (PKK) di Nagari Sungai Pinang, Kecamatan Koto IX Tarusan Kabupaten Pesisir Selatan, Sumatera Barat. PKK merupakan organisasi kemasyarakatan desa yang mampu menggerakkan partisipasi masyarakat desa dalam pembangunan. PKK menjadikan kaum perempuan desa untuk terlibat dalam pembangunan sebagai agen pembangunan tersebut. Sepuluh program yang dimiliki oleh PKK yaitu penghayatan dan pengamalan pancasila, gotong-royong, pangan, sandang, perumahan dan tata laksana rumah tangga, pendidikan dan keterampilan, kesehatan, pengembangan hidup berkoperasi, kelestarian lingkungan hidup, dan perencanaan sehat.

Nagari Sungai Pinang masuk dalam kawasan wisata Mandeh yang diresmikan oleh pemerintah sejak tahun 2014. Beberapa daya tarik wisata yang menarik wisatawan datang ke Nagari Sungai Pinang dapat dilihat dari tiga unsur daya tarik wisata yaitu alam, budaya dan manusia. Nagari sungai Pinang memiliki kondisi alam yang indah dan dijuluki oleh wisatawan dengan "The Hidden Spot Paradise" atau sorga yang tersembunyi. Letak nagari Sungai Pinang yaitu di wilayah perbatasan antara Kabupaten Pesisir Selatan dan Kota Padang.

Dari sisi budaya, kehidupan masyarakat nagari Sungai Pinang sebagai nelayan merupakan daya tarik tertentu bagi wisatawan. Melihat keseharian kehidupan nelayan setiap hari pergi laut untuk mencari ikan, dan pada waktu pagi nelayan mengantarkan hasil melaut ke TPI Bungus Teluk Kabung. Selain itu masyarakat Sungai Pinang memiliki kesenian anak nagari yaitu Randai. Masyarakat Sungai Pinang juga sangat ramah terhadap pendatang atau orang luar, ini sangat mendukung pengembangan pariwisata Nagari yaitu dengan adanya hospitality.

Menarik untuk mengkaji pariwisata di Nagari Sungai Pinang, dengan potensi alam yang dimiliki seperti pantai, laut yang bersih, pulau-pulau yang indah, sungai dan air terjun, kehidupan nelayan yang natural maka Nagari Sungai Pinang berpotensi untuk dikembangkan menjadi pariwisata ekologi atau ekowisata. Ekowisata diartikan berbeda dengan wisata konvensional, Masyarakat Ekowisata Internasional mengartikan sebagai perjalanan wisata alam yang bertanggungjawab dengan cara mengonservasi lingkungan dan meningkatkan kesejahteraan masyarakat lokal. Ekowisata dalam Deklarasi Quebee menyebutkan sebagai bentuk wisata yang mengadopsi prinsip-prinsip pariwisata berkelanjutan. Kegiatan wisata meliputi: (a) secara aktif menyumbang kegiatan konservasi alam dan budaya; (b) melibatkan masyarakat lokal dalam perencanaan, pengembangan dan pengelolaan wisata serta memberikan sumbangan positif terhadap kesejahteraan mereka; (c) dilakukan dalam bentuk wisata independen atau diorganisasi dalam bentuk kelompok kecil (Damanik \& Weber, 2006).

Masyarakat Nagari Sungai Pinang dengan matapencaharian sebagai nelayan termasuk ke dalam masyarakat miskin. (Tomi, 2016). Munculnya Nagari Sungai Pinang sebagai destinasi wisata akan membawa perubahan bagi masyarakat setempat. Tujuan pembangunan pariwisata yaitu untuk meningkatkan pendapatan devisa negara pada khususnya dan pendapatan masyarakat pada umumnya (Tomi, 2016). Selain dari pada itu aktivitas pariwisata juga memiliki dampak pengandaan (multiplier Effect) (Soekidjo, 1997), pariwisata mengembangkan usaha-usaha kepariwisataan yang dapat menguntungkan secara ekonomi bagi banyak sektor usaha. Banyak literatur mengungkap bahwa pembangunan pariwisata memberikan dampak yang positif terutama bidang ekonomi (Pitana, 2005). Akan tetapi dalam pembangunan pariwisata diharapkan partisipasi masyarakat dalam pengembangan pariwisata, supaya mereka tidak hanya sekedar jadi "penonton" akan tetapi juga terlibat aktif dalam pembangunan wisata di Nagari Sungai Pinang dan juga dapat merasakan manfaat positif dari pariwisata.

Berdasarkan penelitian yang telah dilakukan di Nagari Sungai Pinang, masyarakat telah ikut serta berpartisipasi dalam pariwisata. Hanya saja belum semua anggota masyarakat yang terlibat aktif dalam usaha pariwisata (Fitriani, 2017). Padahal masyarakat dapat terlibat aktif dalam bisnis pariwisata dalam penyediaan kebutuhan wisatawan di lokasi wisata seperti usaha penginapan, makanan, souvenir, angkutan wisata dan atraksi wisata seperti kesenian. Pariwisata merupakan suatu usaha yang kompleks bahkan disebut sebagai sebuah industri yang kompleks, dan terkait dengan usaha indutri lainnya (Soekidjo, 1997). 
Pengabdian masyarakat jurusan Sosiologi Fakultas Ilmu Sosial UNP Padang bertujuan untuk meningkatkan ekonomi khususnya ibu-ibu di Nagari Sungai Pinang, melalui aktivitas pelatihan bagi ibu-ibu pegiat PKK membuat souvenir wisata berupa kerajinan tangan sulam bayang. Program PKM ini ditujukan bagi masyarakat calon usaha, dalam hal ini peluang usaha bagi ibu-ibu pegiat PKK dapat dilakukan dengan melatih kelompok PKK untuk membuat kerajinan tangan sulam bayang. Sulam bayang merupakan kerajinan tangan yang telah menjadi ciri khas dari Kabupaten Pesisir Selatan.

Jahitan sulam bayang sebagai souvenir bagi ibu-ibu pegiat PKK memiliki peluang yang cukup besar dengan beberapa argumen, yaitu (1) wisatawan sudah cukup banyak datang berkunjung ke Nagari Sungai Pinang, dan mereka biasa tinggal dalam waktu yang cukup lama. (2) Sungai Pinang pada khususnya dan Pesisir Selatan pada umumnya memiliki jahitan yang khas yang disebut dengan Sulam Bayang sehingga jika usaha ini dikembangkan wisatawan dapat langsung membelinya di Nagari Sungai Pinang. (3) Souvenir yang hendak dikembangkan adalah jahitan sulam bayang dalam ukuran kecil yang dapat digunakan sebagai taplak meja dan sajadah, dan ini sangat berbeda dengan usaha yang telah banyak ada di Pesisir Selatan yaitu jahitan Sulam Bayang dalam ukuran besar yang digunakan untuk membuat pakaian laki-laki atau perempuan serta mukena. Dari sisi ibu-ibu pegiat PKK, alasannya adalah; (1) anggota mitra ini adalah ibu-ibu nelayan yang pada umumnya adalah ibu rumah tangga. Waktu senggang mereka dapat dipakai untuk menghasilkan usaha yang produktif. (2) mitra sudah memiliki mesin jahit yang dapat dipakai untuk pelatihan. (3) usaha ini yang utama adalah dapat melahirkan usaha baru bagi ibu-ibu nelayan pegiat PKK ini dan dapat meningkatkan ekonomi rumah tangga.

\section{Metode Pelaksanaan}

Pengabdian masyarakat dilakukan pada ibu-ibu yang tergabung dalam kelompok Pemberdayaan Kesejahteraan Keluarga (PKK) di Nagari Sungai Pinang. Metode yang dilakukan yaitu melakukan pemberdayaan terhadap ibu-ibu PKK terhadap pemanfaatan budaya lokal yaitu sulaman khas pesisir selatan yang dikenal dengan sulam bayang sebagai salam satu kewirausahaan untuk peningkatan ekonomi rumah tangga dan untuk peningkatan peran serta masyarakat dalam program pembangunan pariwisata di kawasan Mandeh.

Kegiatan ini dilaksanakan dengan penekanan pada metode partisipasi aktif kelompok sasaran. Ibu-ibu PKK yang ikut dalam kegiatan diharapkan berperan aktif dalam kegiatan pengabdian ini. Dari kegiatan ini, diharapkan ibu-ibu PKK dalam menguasai cara pembuatan sulam bayang. Mekanisme kegiatan dilakukan dalam beberapa tahapan yaitu penetapan kelompok sasaran, identifikasi budaya lokal, pelatihan, monitoring dan evaluasi.

Ada dua tahapan evaluasi yang dilakukan dalam pengabdian ini, yaitu:

1. Evaluasi pada akhir pelatihan, yang dimaksudkan untuk mengetahui tingkat pemahaman dan keterampilan peserta, dengan menilai hasil praktek peserta pelatihan. Adapun kriteria penilaian yang digunakan adalah sebagai berikut:

$$
\begin{aligned}
& A=85 \%-100 \%=\text { amat baik } \\
& B=70 \%-84 \%=\text { baik } \\
& C=60 \%-69 \%=\text { Cukup } \\
& D=0 \%-59 \%=\text { kurang }
\end{aligned}
$$

2. Evaluasi pada akhir pelatihan, untuk mengetahui keberhasilan pelaksanaan pengabdianyang dilakukan oleh tim pengabdian masyarakat.

Pelaksanaan pengabdian kepada masyarakat berupa pelatihan keterampilan, melalui 3 (tiga) tahapan, yakni; persiapan, pelaksanaan dan evaluasi. Adapun rincian kegiatan yang dilaksanakan yaitu: 1) Tahap persiapan:

a. Perizinan

b. Persiapan materi, bahan, dan alat. 


\section{2) Tahap Pelaksanaan}

\section{a. Pertemuan 1}

Pembukaan dan penyampaian materi, pengenalan berbagai macam sulaman, sulam Pesisir Selatan, Kegunaan pengabdian masyarakat, memotivasi peserta untuk wirausaha. Kemudian dilanjutkan dengan pengenalan alat dan bahan dan langsung instruktur mendemontrasikan pembuatan taplak meja dan langsung dipraktekkan oleh peserta. Peserta melanjutkan di rumah dalam menyelesaikan sulaman taplak meja dan akan dievaluasi pada pertemuan berikutnya.

\section{b. Pertemuan 2}

Praktek pembuatan tempat tisue. Peserta belajar membuat tempat tisue dengan motif sulam bayang yang dipandu oleh instruktur. Pada kegiatan ini bagi peserta yang belum menyelesaikan pekerjaan kebali melanjutkan pekerjaan di rumah dan dievaluasi pada pertemuan berikutnya.

\section{c. Pertemuan 3}

Praktek pembuatan sajadah dengan motif sulam bayang. Peserta belajar membuat sajadah dengan motif sulam bayang yang dipandu oleh instruktur.

\section{d. Pertemuan 4}

Penyelesaian dilanjutkan dengan evaluasi hasil, pembentukan kelompok usaha sulam bayang dan penutupan.

\section{Hasil dan Pembahasan}

Hasil dari pengabdian kepada masyarakat dijabarkan dalam tiga aspek yakni, kehadiran peserta, partisipasi dan kesungguhan peserta dan hasil praktek dan latihan.

\section{Kehadiran Peserta}

Sasaran yang dilibatkan dalam kegiatan ini adalah ibu-ibu PKK Nagari Sungai Pinang Kabupaten Pesisir Selatan. Pada Pelaksanaan kegiatan jumlah peserta yang hadir sesuai dengan kesepakatan yaitu 16 orang. Selama pertemuan 1,2, dan 4 kehadiran $100 \%$ atau tidak ada yang absen. Seangkan pada pertemuan ke 3 jumlah yang hadir hanya $80 \%$ oleh karena ada peserta yang harus menghadiri pesta perkawinan di Nagari Sungai Pinang.

\section{Partisipasi dan kesungguhan peserta}

Partisipasi dan kesungguhan peserta dapat dikatakan baik. Hal ini dapat terlihat dari kesungguhan peserta dalam mengikuti kegiatan terutama dalam melakukan praktek. Hal ini didukung dengan kesempatan yang diberikan kepada peserta untuk praktek dan menyelesaikan sulaman di rumah. Beberapa dokumentasi kegiatan dapat dilihat pada gambar dibawah ini:

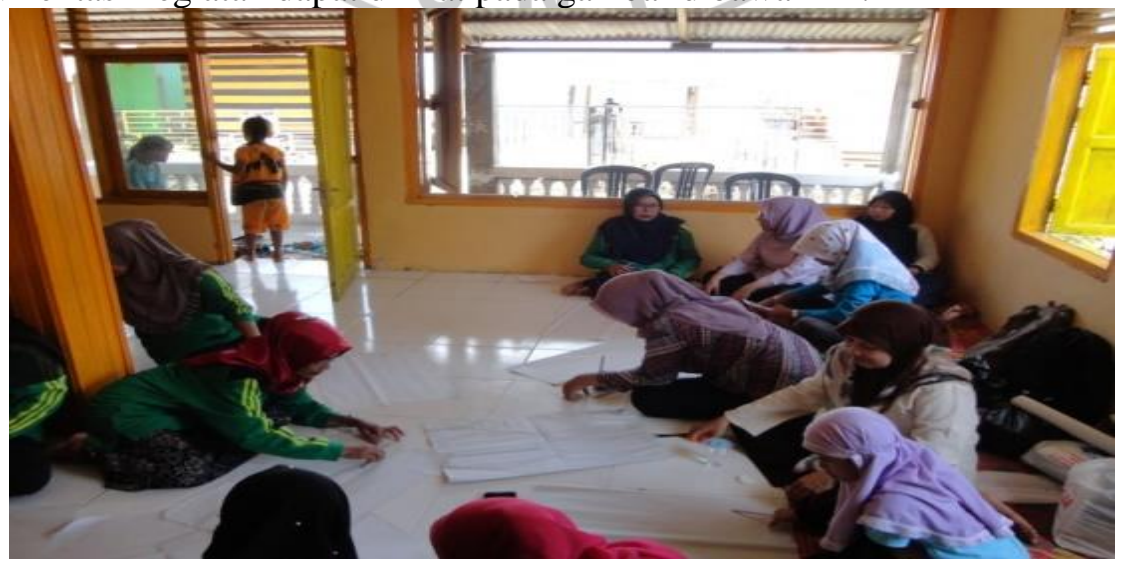

Gambar 1. Peserta melukis gambar di kertas minyak 


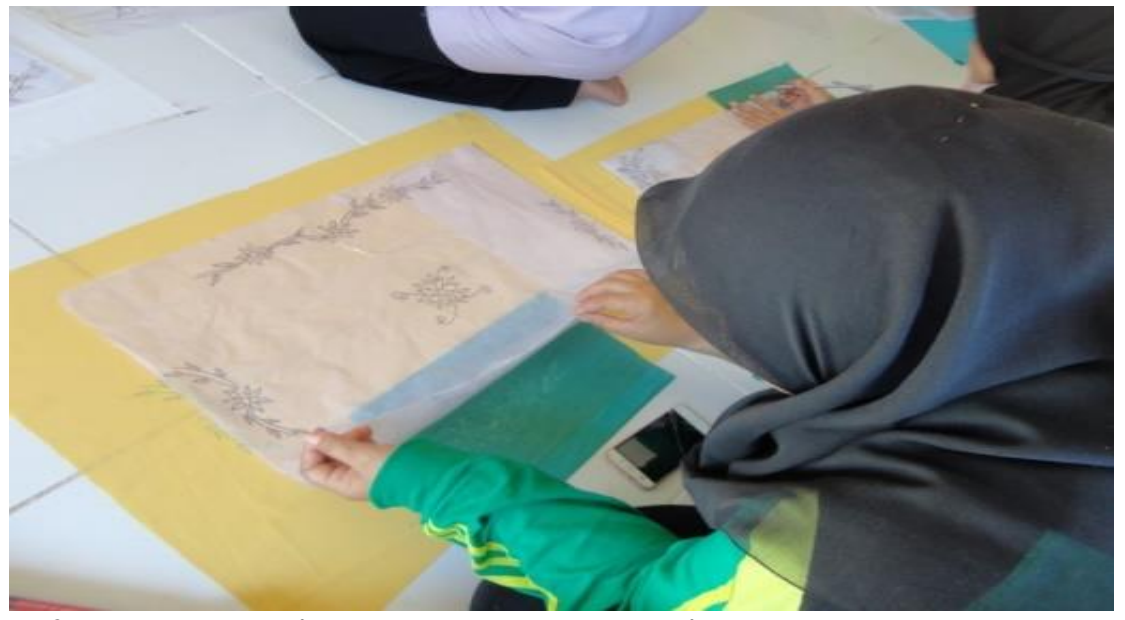

Gambar 2. Peserta memindahkan gambar ke kain untuk pembuatan taplak meja
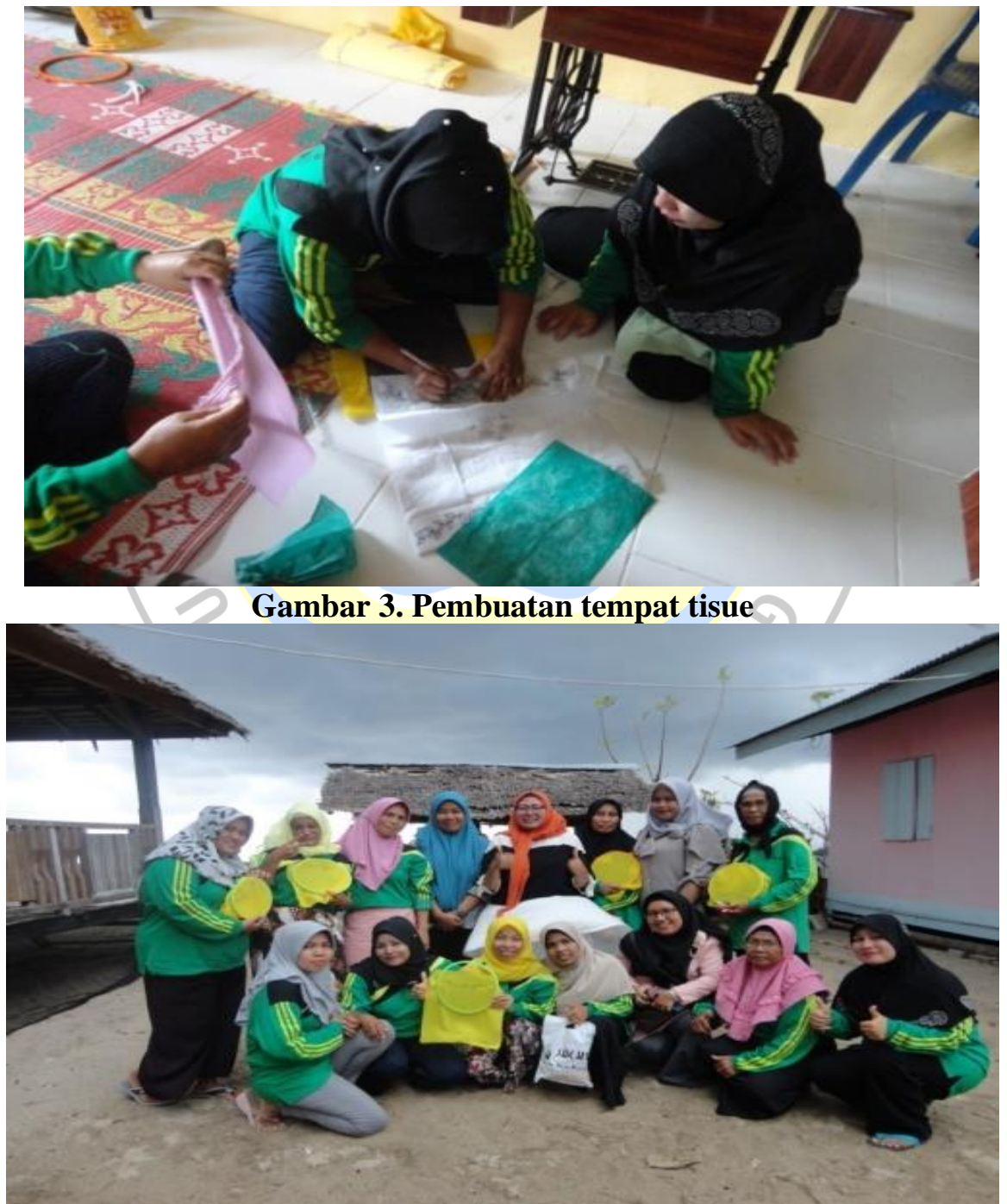

Gambar 4. Ibu - ibu PKK berfoto bersama dengan sulaman 

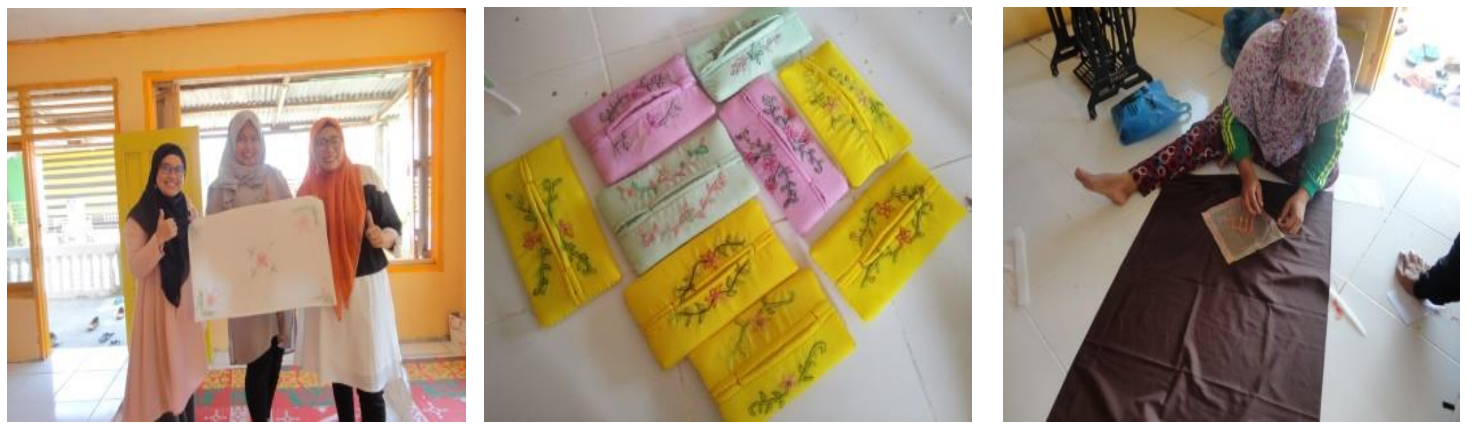

Gambar.5 Menunjukkan hasil pembuatan sulam bayang taplak meja, tempat tisue dan sajadah

3. Hasil pelatihan keterampilan membuat sulam bayang untuk alas meja, tempat tisue, dan sajadah. Berdasarkan dari hasil pengamatan selama pelaksanaan dapat diperoleh:

a. Peserta sangat antusias saat diberikan materi, dan praktek oleh instruktur, hal ini terlihat pada saat diskusi antara peserta dengan instruktur dan juga tim pengabdian masyarakat.

b. Praktek yang dilakukan dalam pembuatan taplak meja, tempat tisue dan sajadah dengan motif sulam bayang. Dalam praktek terlihat antusias para peserta secara individu dan juga secara bersama saling membantu berbagi pengetahuan kepada peserta dalam pembuatan sulam bayang untuk souvenir. Mereka belajar dengan suasana yang amat santai akan tetapi pekerjaan mereka dapat diselesaikan dengan baik.

Mengkaji hasil yang dicapai oleh peserta yaitu $80 \%$ berhasil dengan kriteria baik (B), maksudnya pemahaman peserta mengenai tujuan, dan teknik sudah baik dan dari aspek penyelesaian, keindahan dan kerapian juga baik. Sedangkan hasil dari $20 \%$ peserta memperoleh kriteria amat baik (A) artinya $20 \%$ dari segi pemahaman, teknik dan aspek penyelsaian, keindahan dan kerapian sangat baik. Hambatan bagi peserta yang dirasakan bagi ibu-ibu yang sudah berusia lanjut adalah kesulitan ketika memasukkan benag sulam ke jarum, disebabkan karena mata rabun, namun hal ini dapat diatasi karena adanya "jarum nenek" yang dapat membantu ibu-ibu dalam memasukkan benang sulam ke lubang jarum.

Dari penilaian evaluasi yang dilakukan dapat dianalisa bahwa faktor bagusnya pemahaman dan praktek dari ibu-ibu PKK yaitu: (1) pada tahun lalu mereka sudah mendapatkan praktek pembuatan sulaman tempel, maksudnya menempelkan potongan kain ke kain yang akan digunakan untuk alas meja. (2) bagi ibu-ibu merasakan bahwa pembuatan sulaman bayang ini lebih menyenangkan karena pekerjaan dapat dilanjutkan dengan menyulam sambil duduk ngobrol dengan anggota keluarga atau kerabat ataupun peserta lainnya. (3) sebagian dari ibu-ibu PKK sudah memiliki keterampilan menjahit terutama dengan mesin jahit.

Dari evaluasi terhadap pelatihan ini dibentuk kelompok pengrajin sulam bayang yang dikelola oleh PKK dan bertujuan menjadi kelompok wirausaha yang anggotanya terdiri dari peserta pelatihan ini. Selanjutnya akan dilanjutkan kegiatan ini sebagai penambah inkam rumah tangga nelayan tersebut. Ruangan pelatihan rencana dari ketua penggerak PKK akan dijadikan sebagai tempat display kerajinan tangan ibu-ibu PKK dan dijual sebagai souvenir wisata.

Dalam pelaksanaan kegiatan ini, tim pengabdian masyarakat tidak banyak mendapat hambatan. Hal ini disebabkan karena para peserta merasa membutuhkan pengetahuan dan keterampilan dalam menjahit sulam bayang, dan juga membuat barang-barang yang sangat berguna bagi mereka di rumah dan mempercantik rumah mereka. Selain itu kegiatan ini memberikan motivasi akan adanya peluang usaha untuk mereka. Faktor pendorong yang membuat antusias peserta yaitu ketua penggerak PKK juga terlibat aktif dalam kegiatan ini.

Relevansi kegiatan ini dapat menambah pengetahuan dan keterampilan masyarakat Nagari Sungai Pinang terutama ikut terlibat dalam pelestarian budaya lokal masyarakat Pesisir Selatan. Bagi tim pengabdian masyarakat yaitu penerapan langsung dari materi mata kuliah yang dipelajari sehingga dapat mendharmabaktikan kemampuan sesuai dengan perkembangan zaman. Harapan dari pelatihan ini 
yaitu masyarakat dapat melanjutkan kegiatan ini dan menjadi wirausaha dan akhirnya dapat mendatangkan inkam bagi masyarakat.

Hasil dari kegiatan ini dapat terlihat peningkatan animo dari peserta untuk bersama-sama mengembangkan usaha sulam bayang sebagai salah satu upaya dalam melestarikan budaya lokal dan meningkat pendapatan rumah tangga. Ibu-ibu PKK ini sangat mengharapkan adanya kegiatan yang menambah pengetahuan mereka, dan menginginkan adanya pemantauan, pembinaan dan pengawasan serta evaluasi dari kegiatan yang dilakukan. Tujuannya yaitu agar muncul motivasi di dalam diri mereka untuk berwirausaha dan terus mengembangkan usaha salam bayang ini sebagai souvenir bagi wisatawan yang datang berkunjung ke Nagari Sungai Pinang. Dengan demikian, motivasi yang sudah mantap akan mensukseskan mereka dalam usaha yang berkelanjutan.

Tindakan lanjut dari pemberdayaan masyarakat ini sangat diperlukan untuk menjamin keberlanjutan dari program pengabdian ini. pihak mitra (PKK) akan meneruskan program ini dalam kegiatan PKK, serta membentuk kelompok souvenir sulam bayang. Ibu-ibu PKK yang memiliki minat dan juga kemampuan yang baik dalam pelatihan ini akan menggabungkan diri dalam kelompok wira usaha souvenir.

\section{Kesimpulan}

Dari hasil pelatihan yang dilakukan pada ibu-ibu pegiat PKK di Nagari Sungai Pinang terlihat bahwa animo peserta untuk melestarikan budaya lokal menjadi meningkat. Peningkatan ini didorong oleh karena keinginan untuk merubah kehidupan ekonomi rumah tangga menjadi lebih baik.

\section{Daftar Pustaka}

A.Tomi. (2016). Faktor-Faktor yang Mempengaruhi Pendapatan Nelayan Nagari Sungai Pinang. Skripsi. Universitas Andalas.

Damanik dan Helmut F. Weber. (2006). Perencanaan Ekowisata: Dari Teori ke Aplikasi. Yogyakarta: Pusat Studi Pariwisata dan Penerbit Andi.

Erda Fitriani. (2017). Partisipasi Masyarakatdalam Pembangunan Ekowisata Nagari Sungai Pinang. Laporan Penelitian, Universitas Negeri Padang.

Soekadijo, R. G. (1997). Anatomi Pariwisata. Jakarta: Gramedia.

Spillane, James. (1994). Pariwisata Indonesia: Siasat Ekonomi dan Rekayasa Kebudayaan. Yogyakarta: Kanisius.

Pitana, I Gede . (2005). Sosiologi Pariwisata. Yogyakarta: Andi. 